\title{
Adhesive strength of self-adhesive resins to lithium disilicate ceramic and dentin: effect of dentin chelating agents.
}

\author{
Saker, Samah ; Alnazzawi, Ahmad ; Özcan, Mutlu
}

\begin{abstract}
The aim of this study was to test the effect of different chelating agents on microtensile bond strength (MTBS) of self-adhesive resin cements to dentin. The occlusal surfaces of extracted human mandibular molars (N $=80)$ were cut horizontally to expose sound dentin. The teeth were randomly divided into four groups $(\mathrm{n}=20$ per group) and dentin surfaces were conditioned according to one of the following methods: group C: no treatment (control group); group CH: $0.2 \%$ chitosan; group E: $17 \%$ ethylene diamine tetra acetic acid (EDTA) and group P: $25 \%$ polyacrylic acid (PAA). Lithium disilicate glass ceramic (e.max CAD) blocks were cemented to conditioned dentin surfaces with self-adhesive cements (RelyX Unicem or Clearfil SA) and photo-polymerized. Specimens were stored in distilled water at $37{ }^{\circ} \mathrm{C}$ for $24 \mathrm{~h}$ and thermocycled for 6,000 times. The beams were obtained from bonded ceramic-cement-tooth assemblies and were subjected to the MTBS test $(1 \mathrm{~mm} / \mathrm{min})$. Failure types were analyzed and selected beams were examined under scanning electron microscope. Data (MPa) were analyzed using two-way ANOVA and Tukey's test $(\mathrm{P}<0.05)$. While cement type significantly affected the MTBS results $(\mathrm{P}<0.05)$, no significant difference was observed between the dentin chelating agents $(\mathrm{P}=0.785)$. Interaction terms were not significant $(\mathrm{P}=0.114)$. Control group with no dentin conditioning presented significantly lower results with both cements (RelyX Unicem: $8.1 \pm 1.9$ (a), Clearfil SA: $8 \pm 1.6(\mathrm{a})$ ) than those of conditioned groups $(19.3 \pm 4.2(\mathrm{~b})-24.5 \pm 5.2(\mathrm{~b}))(\mathrm{P}<0.05)$. Failure types were predominantly adhesive in all groups. Chitosan $(2 \%)$, EDTA $(17 \%)$ or PAA $(25 \%)$ could all be used as dentin chelating agents in conjunction with self-adhesive resin cements tested.
\end{abstract}

DOI: https://doi.org/10.1007/s10266-014-0180-3

Posted at the Zurich Open Repository and Archive, University of Zurich

ZORA URL: https://doi.org/10.5167/uzh-127800

Journal Article

Accepted Version

Originally published at:

Saker, Samah; Alnazzawi, Ahmad; Ȯzcan, Mutlu (2016). Adhesive strength of self-adhesive resins to lithium disilicate ceramic and dentin: effect of dentin chelating agents. Odontology / the Society of the Nippon Dental University, 104(1):53-9.

DOI: https://doi.org/10.1007/s10266-014-0180-3 


\section{Adhesive Strength of Self-Adhesive Resins to Lithium Disilicate Ceramic and Dentin: Effect of Dentin Chelating Agents}

\section{Samah Saker • Ahmad Alnazzawi • Mutlu Özcan}

\section{Samah Saker (更)}

Mansoura University, Faculty of Dentistry, Conservative Dentistry Department, Mansoura, Egypt e-mail: samah_saker@hotmail.com

\section{Ahmad Alnazzawi}

Taibah University, School of Dentistry, Substitutive Dental Science Department, Madinah, Saudi Arabia

\section{Mutlu Özcan}

University of Zürich, Dental Materials Unit, Center for Dental and Oral Medicine Clinic for Fixed and Removable Prosthodontics and Dental Materials Science, Plattenstrasse 11, CH-8032, Zürich, Switzerland

Short title: Adhesive strength of self-adhesive resins to dentin

\section{Corresponding to:}

Dr. Samah Saker , Ph.D

Mansoura University

Faculty of Dentistry

Conservative Dentistry Department

Mansoura, Egypt

Tel: +20-12-77446466

e-mail: samah_saker@hotmail.com 
Abstract: The aim of this study was to test the effect of different chelating agents on microtensile bond strength (MTBS) of self-adhesive resin cements to dentin. The occlusal surfaces of extracted human mandibular molars $(\mathrm{N}=80)$ were cut horizontally to expose sound dentin. The teeth were randomly divided into 4 groups ( $\mathrm{n}=20$ per group) and dentin surfaces were conditioned according to one of the following methods: Group C: No treatment (Control group); Group CH: $0.2 \%$ chitosan; Group E: 17\% ethylene diamine tetra acetic acid (EDTA) and Group P: $25 \%$ polyacrylic acid (PAA). Lithium disilicate glass ceramic (e.max CAD) blocks were cemented to conditioned dentin surfaces with self-adhesive cements (RelyX Unicem or Clearfil SA) and photo-polymerized. Specimens were stored in distilled water at $37^{\circ} \mathrm{C}$ for 24 hours and thermocycled for 6000 times. The beams were obtained from bonded ceramic-cement-tooth assemblies and they were subjected to the MTBS test $(1 \mathrm{~mm} / \mathrm{min})$. Failure types were analyzed and selected beams were examined under scanning electron microscope. Data (MPa) were analyzed using two-way ANOVA and Tukey's test $(P<0.05)$. While cement type significantly affected the MTBS results $(P<0.05)$, no significant difference was observed between the dentin chelating agents $(P=0.785)$. Interaction terms were not significant $(P=0.114)$. Control group with no dentin conditioning presented significantly lower results with both cements (RelyX Unicem: $8.1 \pm 1.9^{\mathrm{a}}$, Clearfil SA: $8 \pm 1.6^{\mathrm{a}}$ ) than those of conditioned groups $\left(19.3 \pm 4.2^{\mathrm{b}}-24.5 \pm 5.2^{\mathrm{b}}\right)(P<0.05)$. Failure types were predominantly adhesive in all groups. Chitosan (2\%), EDTA (17\%) or PAA $(25 \%)$ could all be used as dentin chelating agents in conjunction with self-adhesive resin cements tested.

Keywords Adhesion $\bullet$ Adhesive cement $\bullet$ Dentin chelating agents $\bullet$ Self-adhesive cement $\bullet$ Smear layer 


\section{Introduction}

The technology of Computer Aided Design/Computer Aided Manufacturing (CAD/CAM) enabled clinicians to manufacture indirect restorations from aesthetic all ceramic materials at chair-side in a single patient visit. Chair-side CAD/CAM applications offer many advantages to patients including elimination of laboratory processing costs and the need for temporization of the prepared tooth structure [1]. Durable adhesion between dental tissues and ceramics plays a crucial role in the success of restorations that do not have retentive properties [2-6]. When bonding ceramic restorations to dental substrates, it is crucial to ensure optimal adhesion of resin cement to both the dentin and ceramic surface [7-9]. Thus, the integrity of dentin-cement and cement-ceramic interface is essential for the survival of bonded restorations $[10,11]$.

The adhesion of conventional resin-based luting cements is affected by the surface roughness of the preparation and dentin-cleansing agents used [12-14]. Resin cements infiltrate the dentinal tubules, exposed network of collagen and establish a micromechanical interlocking [15-17]. Selfadhesive resin cements on the other hand, were developed to simplify the technique-sensitive multistep procedures. When applied directly on the smear layer covering the dentin, with no pretreatments, the acidic monomers within self-adhesive cements could demineralize the dentin and infiltrate through the mineralized tissue [18-21]. However, commercially available self-adhesive cements show variations in the amount of acidic monomers in their composition [22,23]. Yet, limited etching potential of acidic monomers may cause poor adhesion and impair ideal cement infiltration through dentin [18-20]. Consequently, self-adhesive resin cements present lower bond strength to dentin compared to conventional multistep resin cements [18-20]. 
In order to enhance the bond strength of self-adhesive cements to dentin, different conditioning methods were suggested such as air abrasion, mechanical cleaning with pumice slurry, sodium hypochlorite irrigation, chlorhexidine digluconate ( $\mathrm{CHX}$ ), polyacrylic acid (PAA), and ethylene diamine tetra acetic acid (EDTA) [23-32]. Recently, the use of chitosan was suggested as a more biocompatible chelating agent to condition the smear layer on dentin [33]. Chitosan is a natural polysaccharide that has attracted attention in dental research owing to its biodegradability, bioadhesion, biocompatibility and lack of toxicity [34]. Chitosan is obtained after deacetylation of chitin that is found in shrimp and crab shells and became ecologically interesting for many applications as a naturally abundant cheap product $[35,36]$. However, chelating effect of chitosan containing adhesives on dentin compared to other agents also considering the adhesion onto the restoration material has not been investigated.

The objectives of this study therefore were to test b) the effect of different chelating agents on microtensile bond strength (MTBS) of self-adhesive resin cements to dentin and b) to analyze the failure types after debonding. The null hypotheses tested were that a) chitosan as a chelating agent would not result in different MTBS results compared to traditional EDTA and PPA and b) chelating agents would not increase MTBS compared to control group.

\section{Materials and methods}

The brands, manufacturers, chemical compositions and application procedures of the materials used in this study are listed in Table 1.

\section{Specimen preparation}

Freshly extracted human permanent mandibular molars $(\mathrm{N}=80)$, free of cracks, caries and restorations, were collected from patients after informed consent of the patients. The teeth used in this study were either impacted third molars or grade III mobile molars from diabetic patients or 
patients with chronic periodontitis and otherwise healthy. The collected teeth were cleaned and stored in $0.5 \%$ chloramine solution at $\left(4^{\circ} \mathrm{C}\right)$ for up to 6 months after extraction. Approval to use human teeth was granted by the Research Ethics Committee at Mansoura University, Egypt. Prior to the experiments, power analysis was performed (SAS/STAT 12.1 software, SAS Institute Inc, Cary North Carolina, USA) to determine the number of specimens required in each test group for statistical differences.

The occlusal surfaces of teeth were cut horizontally to expose sound dentin and further ground flat with 180-, 320-, and 600-grit SiC-papers (Buehler Ltd, Lake Bluff, USA) to obtain a uniform smear layer under running. Teeth were stored in distilled water at all times. The teeth were randomly divided into 4 groups ( $n=20$ per group) and dentin surfaces were conditioned according to one of the following methods:

\section{Dentin conditioning}

Group C: No treatment (Control group). After cutting and ground finishing the dentin surfaces, they were rinsed with distilled water for 5 seconds.

Group $\mathrm{CH}$ : Dentin surfaces were conditioned with cotton pellets soaked in $0.2 \%$ chitosan solution for three minutes $[37,38](\mathrm{pH}=3.2$, Fig. 1a). For preparation of the $0.2 \%$ chitosan solution, $0.2 \mathrm{~g}$ of chitosan was diluted in $100 \mathrm{~mL}$ of $1 \%$ acetic acid, and the mixture was agitated using a magnetic mixer for 2 hours.

Group E: Dentin surfaces were conditioned with cotton pellets soaked in $17 \%$ EDTA $(p H=10.3)$ (Fig. 1b) in aqueous solution for 1 minute [20]. All treated teeth were rinsed with distilled water for 30 seconds and dried with absorbent paper to avoid desiccation of dentin [32].

Group P: Dentin surfaces were conditioned with 25\% PPA (Ketac Conditioner, 3M ESPE, Seefeld, Germany) (Fig. 1c) for 10 seconds [32]. 


\section{Preparation of ceramic blocks}

Lithium disilicate glass ceramic (IPS e.max CAD, Ivoclar Vivadent AG, Schaan, Liechtenstein) blocks (Shade A1) were cut into 80 blocks ( $3 \mathrm{~mm} \times 6 \mathrm{~mm} \times 2 \mathrm{~mm}$ ) in precrystalline stage using a slow speed diamond saw. The dimensions of each block were measured using a caliper. Crystallization of ceramic blocks was carried out in a furnace (P700, Ivoclar Vivadent AG) according to the firing program recommended by the manufacturer: standby temperature at $403^{\circ} \mathrm{C}$, rate of increase for the first temperature at $60^{\circ} \mathrm{C} / \mathrm{min}$, first closing time for 5 minutes; rate of increase for the second temperature at $30^{\circ} \mathrm{C} / \mathrm{min}$, second closing time for 10 minutes; first vacuum-on temperature at $550^{\circ} \mathrm{C}$, first vacuum-off-temperature at $770^{\circ} \mathrm{C}$; second vacuum-on temperature at $770^{\circ} \mathrm{C}$, second vacuum-off temperature at $850^{\circ} \mathrm{C}$; final firing temperature at $850^{\circ} \mathrm{C}$, long-term cooling at $700^{\circ} \mathrm{C}$ at a cooling rate of $20^{\circ} \mathrm{C} / \mathrm{min}$.

\section{Cementation procedures}

The bonding surfaces of ceramic slices were air-abraded with $50 \mu \mathrm{m}$ aluminum oxide particles (Korox, Bego, Bremen, Germany). They were then cleaned in an ultrasonic bath in distilled water (Healthsonics, Livermore, USA) for 10 minutes to eliminate any contamination on the surfaces. Bonding surfaces of ceramic blocks were etched with $9.6 \%$ hydrofluoric acid (Porcelain etch, Pulpdent, Watertown, USA) for 90 seconds, rinsed for 30 seconds with water spray, air dried, and silanized with a silane coupling agent (Silane Pulpdent, Pulpdent) for 60 seconds and then airdried for $30 \mathrm{~s}$.

\section{Microtensile bond strength test}

Ceramic blocks were cemented to conditioned dentin surfaces with one of the two self-adhesive cements: RelyX Unicem (3M ESPE, Seefled, Germany) or Clearfil SA (Kuraray Noritake Dental Inc., Tokyo, Japan), following instructions of each manufacturer. Resin cement was applied to 
dentin surfaces and ceramic blocks were bonded under a load of $300 \mathrm{~g}$ to create a uniform resin thickness. Excess resin cement was removed with a brush. Resin cement was photo-polymerized from each direction for 40 seconds using a halogen photo-polymerization unit (Hilux Ultra Plus, Benlioglu Dental, Ankara, Turkey) with an output of $600 \mathrm{~mW} / \mathrm{cm}^{2}$. The specimens were stored in distilled water for 24 hours at $37^{\circ} \mathrm{C}$ and thermocycled for 6000 times $\left(5-55 \pm 2^{\circ} \mathrm{C}\right.$, dwell time: 20 seconds, transfer time: 5 seconds). The beams $(\sim 1 \mathrm{~mm} \times 1 \mathrm{~mm})$ were obtained from bonded ceramic-cement-tooth assemblies using a diamond slow speed blade (Buehler, Series 15LC Diamond, Buehler) under constant cooling water. Digital calipers (Thermo Fisher Scientific Inc., Pittsburgh, USA) were used to measure the dimensions of each beam and bonded area for each beam was calculated. The beams were examined under optical microscope and only intact beams were included in this study. The beams were then fixed in the jig of the Universal Testing Machine (Lloyd Instrument, Type 500, Hants, United Kingdom) using cyanoacrylate adhesive (Zapit-brand, Dental Ventures of America, Ventura, USA). Specimens were stressed under tension to failure at a cross-head of $1 \mathrm{~mm} / \mathrm{min}$. Maximum tensile load was divided by cross-sectional area of each beam to obtain MTBS data (MPa).

After debonding, the specimens were examined under optical stereomicroscope (Carl-Zeiss, Oberkochen, Germany) at $x 40$ to analyze the failure types. The failure types were classified as follows: a) Adhesive (failure at adhesive layer, no resin left on dentin), b) Cohesive (failure in dentin or luting cement), or c) Mixed (combination of adhesive failure between resin and dentin and cohesive failure in the cement).

Selected 3 to 5 beams from each group were further for examined under Scanning Electron Microscope (SEM 515, Phillips, Eindhoven, The Netherlands) at x1000 at 15 to $30 \mathrm{~kW}$.

\section{Statistical analysis}


Statistical analysis was performed using SPSS 11.0 software for Windows (SPSS; Chicago, IL, USA). Levene test showed that MTBS data (MPa) were homogeneously distributed. Data were then submitted to two-way ANOVA with the bond strength as the dependent variable and dentin chelating agents ( 3 levels; chitosan, EDTA, PPA) and luting composite type (2 levels: RelyX Unicem vs Clearfil SA) as independent variables. Multiple comparisons were made using Tukey’s test. Pre-test failures during cutting procedures were excluded from data analysis. Twenty intact beams could be obtained in each group from the mid portion of the bonded area. In all tests, statistical significance was set at $\mathrm{P}<0.05$.

\section{Results}

While cement type significantly affected the MTBS results $(P<0.05)$, no significant difference was observed between the dentin chelating agents $(P=0.785)$. Interaction terms were not significant $(P=0.114)$. Control group with no dentin conditioning presented significantly lower results with both cements (RelyX Unicem: $8.1 \pm 1.9^{a}$, Clearfil SA: $\left.8 \pm 1.6^{a}\right)$ than those of conditioned groups $\left(19.3 \pm 4.2^{b}\right.$ $\left.-24.5 \pm 5.2^{\mathrm{b}}\right)(P<0.05)($ Table 2$)$.

Failure types were predominantly adhesive in all groups, being more frequent in the control group (Table 3).

SEM examinations from debonded specimens revealed that in adhesive failures most of the smear layer was removed and most of the dentinal tubules were clearly opened. After treatment with chitosan, EDTA and PAA mixed failures were evident where varying amounts of resin cement obliterated the tubules but resin infiltration was not evident in large areas of dentin surfaces (Figs. 2a-d). 


\section{Discussion}

This study was undertaken to study the effect of different chelating agents on MTBS of selfadhesive resin cements to dentin. Since the chelating agents did not show significant differences between each other but presented significantly higher results than those of the control groups, the first hypothesis tested could be accepted but the second one could be rejected.

The long-term success of modern dental adhesives is limited. The most reported causes of their failure are retention loss or marginal degradation [39]. Many factors were proposed to be involved in bond degradation and different methods were used to reproduce clinical situations and simulate the oral environment in order to test the dentin bonding durability $[37,38]$. Among these methods, thermal cycling, load cycling and prolonged water or artificial saliva incubation were commonly used $[39,40]$. Thermocycling protocols used to evaluate bond durability ranged from 100 cycles to more than 50.000 cycles [41]. In the present study, the specimens were subjected to 6.000 thermal cycles that is more than the regimen proposed by the ISO standard (5000 cycles) [42]. After this aging condition, the control groups with both self-adhesive resin cements showed the lower MTBS results compared to other groups where dentin surfaces were conditioned with chelating agents.

The use of $0.2 \%$ chitosan solution, even in such a low concentration, was able to remove smear layer and showed MTBS results comparable to EDTA and PAA treatments. Chitosan is known to remove the inorganic content of the smear layer on the dentin surface [33]. Despite the working mechanism of chitosan is not fully understood, it is assumed that adsorption, ionic exchange and chelation are responsible for the formation of reaction between the substrate and the metallic ions. This type of interaction depends highly on the ions involved, the chemical structure of chitosan, and the $\mathrm{pH}$ of the solution. The chitosan polymer is formed of a chain of several dimers of chitin. 
Like EDTA molecule, the chitin dimer (Fig. 1a) has two nitrogen atoms with pairs of free electrons that are responsible for its ionic reactions. In acidic medium, the amino groups present in the bipolymer are protonated $\left(\mathrm{NH}^{+}\right)$, resulting in its overall charge. Subsequently, adsorption occurs by attraction of molecules to this biopolymer form. Complexes of chitosan and metal ions are most probably formed by the mechanisms of adsorption, ion exchange and chelation $[40,43]$. Pimentaet al [44] reported that the $0.2 \%$ chitosan solution $(\mathrm{pH}=3.2)$ has a capacity to reduce dentin microhardness similar to that of $15 \%$ EDTA $(\mathrm{pH}=7.25)$ representing similar demineralization potential. The effect of $0.2 \%$ chitosan applied for 3 minutes was the most effective for removing the smear layer and smear plug with minimal erosive effect on dentin substrate as suggested previously in the study of Silva et al [38].

On the other hand, EDTA is a molecule containing 4 carboxylic acid groups that can chelate calcium. It dissolves the dentin minerals without changing its protein content, thereby, no major alterations of the native fibrillar collagen [45]. Dentin surface treatment with EDTA showed favourable effects on the resin-dentin adhesion with increased immediate shear bond strength [28]. Pretreatment with 25\% PAA, a mild acidic agent, resulted in a significant increase in the MTBS results with both self-adhesive cements tested. PAA has been widely used as a dentin conditioner to enhance adhesion of glass ionomer cements. PAA contains numerous carboxyl groups that can form many hydrogen bonds and promote cleaning and wetting of dentin substrate [32]. Dentin conditioning with PAA resulted in a significantly high MTBS values with both resin cements compared to Control groups. The mild acidic effect of PAA could partially remove the smear layer, leaving dentin mineral phase, thus enhancing the chemical reaction between resin cement and dentin substrate [29]. Both cement types used in this study are self-etching and selfadhesive luting agents that produce no visible hybrid layer $[20,32]$. Poor results obtained in the 
control group (no treatment) in this study could be explained by the presence of most of the smear layer where water spray failed to remove it effectively. The presence of remnants of smear layer blocked the dentinal tubules orifices allowing no resin infiltration. In this context, the presence and absence of the smear layer needs to be considered when using chelating agents. Removal of the smear layer increases the permeability of the dentin tubules permitting fluid flow from outside the pulp chamber, and vice versa, and also eliminating the microorganisms but this may also induce tooth sensitivity [46]. On the other hand, closed dentin tubuli with the smear layer does not permit access of bacteria towards the pulp and irritation of the pulp by toxic chemicals such as acids. Complete or partial removal of the smear layer by applying acidic or chelating solutions should overweigh such pros and cons of the presence of smear layer.

In this study, mainly adhesive failure types were experienced in all groups. It can be stated that application of any of the chelating agents increased the bond strength of the tested self-adhesive cement but did not increase the interfacial adhesion more than the cohesive strength of dentin or the ceramic. This could be partially attributed to the torsional stresses occurring during cutting the beams that occurs mainly during cutting the ceramic part of the dentin-cement-ceramic assembly [3]. The results of this study need to be verified with other test methods.

\section{Conclusions}

The bond strength results to dentin were more than twice the control group when dentin was activated with chelating agents. Chitosan, $17 \%$ EDTA or $25 \%$ PAA could all be used as dentin chelating agents when cementing ceramic restoration in conjunction with self-adhesive resin cements, providing that the failure types were predominantly adhesive in all groups. 


\section{Conflict of Interest}

The authors declare that they have no conflict of interest. 


\section{References}

1. Mormann WH. The evolution of the CEREC system. J Am Dent Assoc. 2006;137:7-13.

2. Frankenberger $\mathrm{R}$, Petschelt $\mathrm{A}$, Kramer $\mathrm{N}$. Leucite reinforced glass ceramic inlays and onlays after six years: clinical behavior. Oper Dent. 2000;25:459-65.

3. Marocho SM, Özcan M, Amaral R, Bottino MA, Valandro LF. Effect of resin cement type on the microtensile bond strength to lithium disilicate ceramic and dentin using different test assemblies. $J$ Adhes Dent. 2013;15:361-8.

4. Saker S, Ibrahim F, Özcan M. Effect of different surface treatments on adhesion of In-Ceram zirconia to enamel and dentin substrates. J Adhes Dent. 2013;15:369-76.

5. Passos SP, Kimpara ET, Bottino MA, Júnior GC, Rizkalla AS. Bond strength of different resin cement and ceramic shades bonded to dentin. J Adhes Dent. 2013;15:461-6.

6. Passos SP, Souza RO, Michida SM, Zamboni SC, de Oliveira SH. Effects of cement-curing mode and light-curing unit on the bond durability of ceramic cemented to dentin. Braz Oral Res. 2013;27:169-75.

7. Stewart GP, Jain P, Hodges J. Shear bond strength of resin cements to both ceramic and dentin. J Prosthet Dent. 2002;88:277-84.

8. Nagai $\mathrm{T}$, Kawamoto $\mathrm{Y}$, Kakehashi $\mathrm{Y}$, Matsumura $\mathrm{H}$. Adhesive bonding of a lithium disilicate ceramic material with resin-based luting agents. J Oral Rehabil. 2005;32:598-605.

9. Simon JF, de Rijk WG, Hill J, Hill N. Tensile bond strength of ceramic crowns to dentin using resin cements. Int J Comput Dent. 2011;14:309-19.

10. Dalby R, Ellakwa A, Millar B, Martin FE. Influence of immediate dentin sealing on the shear bond strength of pressed ceramic luted to dentin with self-etch resin cement. Int $\mathrm{J}$ Dent. 2012;2012:310702-310709. 
11. de Castro HL, Passos SP, Zogheib LV, Bona AD. Effect of cement shade and light-curing unit on bond strength of a ceramic cemented to dentin. J Adhes Dent. 2012;14:155-60.

12. Xie J, Powers JM, McGuckin RS. In vitro bond strength of two adhesives to enamel and dentin under normal and contaminated conditions. Dent Mater. 1993;9:295-9.

13. Kelsey WP, Latta MA, Blankenau RJ. Effect of provisional restorations on dentin bond strengths of resin cements. Am J Dent. 1998;11:67-70.

14. Hill EE. Dental cements for definitive luting: A review and practical clinical considerations. Dent Clin North Am. 2007;51:643-58.

15. Leirskar J, Nordbo $\mathrm{H}$. The effect of zinc oxide-eugenol on the shea bond strength of a commonly used bonding system. Endod Dent Traumatol. 2000;16:265-8.

16. Grasso C, Caluori D, Goldstein G, Hittelman E. In vivo evaluation of three cleansing techniques for prepared abutment teeth. J Prosth Dent. 2002;88:437-41.

17. Mair L, Padipatvuthikul P. Variables related to materials and preparing for bond strength testing irrespective of the test protocol. Dent Mater. 2010;26:e17-23.

18. Sarac D, Sarac YS, Kulunk S, Kulunk T. Effect of the dentin cleansing techniques on dentin wetting and on the bond strength of a resin luting agent. J Prosth Dent. 2005;94:363-9.

19. Yang B, Ludwig K, Adelung R, Kern M. Micro-tensile bond strength of three luting resins to human regional dentin. Dent Mater. 2006;22:45-56.

20. Kambara K, Nakajima M, Hosaka K, Takahashi M, Thanatvarakorn O, Ichinose S, et al. Effect of smear layer treatment on dentin bond of self-adhesive cements. Dent Mater. 2012;31:980-7.

21. Lisboa DS, Santos SV, Griza S, Rodrigues JL, Faria-e-Silva AL. Dentin deproteinization effect on bond strength of self-adhesive resin cements. Braz Oral Res. 2013;27:73-5. 
22. Mazzitelli C, Monticelli F, Toledano M, Ferrari M, Osorio R. Dentin treatment effects on the bonding performance of self-adhesive resin cements. Eur J Oral Sci. 2010;118:80-6.

23. Di Hipólito V, Rodrigues FP, Piveta FB, AzevedoLda C, Bruschi Alonso RC, Silikas N et al. Effectiveness of self-adhesive luting cements in bonding to chlorhexidine-treated dentin. Dent Mater. 2012;28:495-501.

24. Ayad MF, Rosenstiel SF, Hassan MM. Surface roughness of dentin after tooth preparation with different rotary instrumentation. J Prosthet Dent. 1996;75:122-8.

25. Toledano M, Osorio R, Perdigao J, Rosales JI, Thompson JY, Cabrerizo-Vilchez MA. Effect of acid etching and collagen removal on dentin wettability and roughness. J Biomed Mater Res.1999;47:198-203.

26. Hikita K, Van Meerbeek B, De Munck J, Ikeda T, Van Landuyt K, Maida T et al. Bonding effectiveness of adhesive luting agents to enamel and dentin. Dent Mater. 2007;23:71-80.

27. Lührs AK, Guhr S, Günay H, Geurtsen W. Shear bond strength of self-adhesive resins compared to resin cements with etch and rinse adhesives to enamel and dentin in vitro. Clin Oral Invest. 2010;14:193-9.

28. Tonial D, Ghiggi PC, Lise AA, Burnett LH Jr, Oshima HM, Spohr AM. Effect of conditioner on microtensile bond strength of self-adhesive resin cements to dentin. Stomatologija. 2010;12:73-9. 29. Pavan S, dos Santos PH, Berger S, Bedran-Russo AK. The effect of dentin pretreatment on the microtensile bond strength of self-adhesive resin cements. J Prosthet Dent. 2010;104:258-64.

30. El-Askary FS, Nassif MS. The effect of the pre-conditioning step on the shear bond strength of nano-filled resin-modified glass-ionomer to dentin. Eur J Dent. 2011;5:150-6.

31. Ferracane JL, Stansbury JW, Burke FJT: Self-adhesive resin cement-chemistry, properties and clinical considerations. J Oral Rehabil. 2011;38:295-314. 
32. Broyles AC, Pavan S, Bedran-Russo AK. Effect of dentin surface modification on the microtensile bond strength of self-adhesive resin cements. J Prosthodont. 2013;22:59-62.

33. Silva PV, Guedes DF, Nakadi FV, Pécora JD, Cruz-Filho AM. Chitosan: a new solution for removal of smear layer after root canal instrumentation. Int Endod J. 2013;46:332-8.

34. Akncbay H, Senel S, Ay ZY. Application of chitosan gel in the treatment of chronic periodontitis. J Biomed Mater Res. Part B, Appl Biomater. 2007;80:290-6.

35. Peter MG. Applications and environmental aspects of chitin and chitosan. J Macromol Sci. 1995;32:629-40.

36. DaSilva L, Finer Y, Friedman S, Basrani B, Kishen A. Biofilm formation within the interface of bovine root dentin treated with conjugated chitosan and sealer containing chitosan nanoparticles. $J$ Endod. 2013;39:249-53.

37. Rinaudo M, Pavlov G, Desbrie'res J. Influence of acetic acid concentration on the solubilization of chitosan. Polymer. 1999;40;7029-32.\$

38. Silva PV, Guedes DF, Pécora JD, da Cruz-Filho AM. Time-dependent effects of chitosan on dentin structures. Braz Dent J. 2012;23:357-61.

39. Manuja N, Nagpal R, Pandit IK. Dental adhesion: mechanism, techniques and durability. J Clin Pediatr Dent. 2012;36:223-34.

40. Hülsmann M, Heckendorff M, Lennon A. Chelating agents is root canal treatment mode of action and indications for their use. Int Endod J. 2003;36:810-30.

41. Feitosa VP, Sauro S, Watson TF, et al. Evaluation of the micro-mechanical strength of resin bonded-dentin interfaces submitted to short-term degradation strategies. J Mech Behav Biomed Mater. 2012; 15:112-20. 
42. ISO. Guidance on testing of adhesion to tooth structure. International Organization for Standardization1994. TR 11405,1-14 Geneva (Switzerland).

43. Rhazi M, Desbrie'res J, Tolaimate A et al. Influence of the nature of the metal ions on the complexation with chitosan: Application to the treatment of liquid waste. Eur Polym J. 2002;38:1523-30.

44. Pimenta JA, Zaparolli D, Pécora JD, Cruz-Filho AM. Chitosan: effect of a new chelating agent on the microhardness of root dentin. Braz Dent J. 2012;23:212-7.

45. Sauro S, Mannocci F, Toledano M, Osorio R, Pashley DH, Watson TF. EDTA or $\mathrm{H} 3 \mathrm{PO} 4 / \mathrm{NaOCl}$ dentine treatments may increase hybrid layers' resistance to degradation: $\mathrm{A}$ microtensile bond strength and confocal-micropermeability study. J Dent. 2009;37:279-88.

46. Pashley D. Clinical correlations of dentin structure and function. J Prosthet Dent. 1991;66:77781. 


\section{Figure legends:}

\section{Tables}

Table 1 Brands, manufacturers, chemical compositions and luting procedures of the resin cements used in this study

Table 2 Microtensile bond strength mean values $(\mathrm{MPa}) \pm$ standard deviations of lithium disilicate ceramic bonded onto dentin using two self-adhesive cements after conditioning dentin with different chelating agents. Lowercase letters in the same column and capital letters in the same row indicate no significant difference $(P<0.05)$

Table 3 Frequency of failure types in percentages, a) Adhesive (failure at adhesive layer, no resin left on dentin), b) cohesive (failure in dentin or luting cement), or c) mixed (combination of adhesive failure between resin and dentin and cohesive failure in the cement)

\section{Figures}

Figs. 1 a-c. Chemical compositions of a) Chitosan Dimer, b) EDTA and c) Polyacrylic acid

Figs. 2 a-d. Representative SEM images of dentin after debonded dentin beams after a) Adhesive failure in Control group. Note that the dentin tubuli were exposed in large amounts (white arrow), and Mixed failure type in b) Chitosan group, c) EDTA and d) Polyacrylic acid with partial obliteration of dentin tubuli with resin cement $\left(^{*}\right)$ 


\section{Tables:}

Table 1 Brands, manufacturers, chemical compositions and luting procedures of the resin cements used in this study

\begin{tabular}{|c|c|c|c|}
\hline Brand & Manufacturer & Chemical composition & Luting procedure \\
\hline RelyX Unicem & $\begin{array}{c}\text { 3M ESPE, } \\
\text { Seefeld, Germany }\end{array}$ & $\begin{array}{l}\text { Methacrylate monomers } \\
\text { containing phosphoric acid } \\
\text { groups, methacrylate } \\
\text { monomers, silanated fillers, } \\
\text { initiator components, and } \\
\text { stabilizers }\end{array}$ & $\begin{array}{l}\text { Triturate the capsule in a } \\
\text { triturating device for } 15 \\
\text { seconds, } \\
\text { apply the mix and } \\
\text { polymerize for } 40 \\
\text { seconds }\end{array}$ \\
\hline Clearfil SA & $\begin{array}{c}\text { Kuraray Noritake } \\
\text { Dental Inc., Tokyo, } \\
\text { Japan }\end{array}$ & $\begin{array}{c}\text { MDP, bis-GMA, TEGDMA, } \\
\text { other dimethacrylate monomers, } \\
\text { barium, glass filler, colloidal } \\
\text { silica, } \\
\text { surface treated sodium fluoride, } \\
\text { initiators, stabilizers, }\end{array}$ & $\begin{array}{l}\text { Hand mix for } 10 \mathrm{~s} \text {, } \\
\text { apply the mix and } \\
\text { polymerize for } 40 \\
\text { seconds }\end{array}$ \\
\hline
\end{tabular}




\begin{tabular}{|c|c|c|}
\hline Dentin Conditioning Method & RelyX Unicem & Clearfil SA \\
\hline Control (No treatment) & $8.1 \pm 1.9^{\mathrm{a}, \mathrm{A}}$ & $8.0 \pm 1.6^{\mathrm{a}, \mathrm{A}}$ \\
\hline $0.2 \%$ Chitosan $(\mathrm{pH}=3.2)$ & $23.7 \pm 2.4^{\mathrm{b} . \mathrm{B}}$ & $22.9 \pm 2.5^{\mathrm{b}, \mathrm{B}}$ \\
\hline $17 \%$ EDTA $(\mathrm{pH}=0.3)$ & $22.5 \pm 4.5^{\mathrm{b}, \mathrm{B}}$ & $19.3 \pm 4.2^{\mathrm{b}, \mathrm{B}}$ \\
\hline $25 \%$ Poly acrylic acid & $24.5 \pm 5.2^{\mathrm{b}, \mathrm{B}}$ & $20.6 \pm 2.9^{\mathrm{b}, \mathrm{B}}$ \\
\hline
\end{tabular}

Table 2 Microtensile bond strength mean values (MPa) \pm standard deviations of lithium disilicate ceramic bonded onto dentin using two self-adhesive cements after conditioning dentin with different chelating agents. Lowercase letters in the same column and capital letters in the same row indicate no significant difference $(P<0.05)$ 


\begin{tabular}{|c|c|c|c|c|c|}
\hline \multirow{2}{*}{$\begin{array}{l}\text { Dentin Conditioning } \\
\text { Method }\end{array}$} & \multirow[t]{2}{*}{ Cement Type } & & \multicolumn{3}{|c|}{ Failure Type (\%) } \\
\hline & & $\begin{array}{l}\text { Tested } \\
\text { beams } \\
\text { (n) }\end{array}$ & Adhesive & Cohesive & Mixed \\
\hline \multirow[t]{2}{*}{ Control group } & RelyX Unicem & 20 & 60 & 10 & 30 \\
\hline & Clearfil SA & 20 & 60 & 20 & 20 \\
\hline \multirow[t]{2}{*}{$2 \%$ Chitosan } & RelyX Unicem & 20 & 50 & 20 & 30 \\
\hline & Clearfil SA & 20 & 60 & 10 & 30 \\
\hline \multirow[t]{2}{*}{$17 \%$ EDTA } & RelyX Unicem & 20 & 60 & 20 & 20 \\
\hline & Clearfil SA & 20 & 60 & 20 & 20 \\
\hline \multirow[t]{2}{*}{ 25\% Polyacrylic acid } & RelyX Unicem & 20 & 50 & 20 & 30 \\
\hline & Clearfil SA & 20 & 60 & 20 & 20 \\
\hline
\end{tabular}

Table 3 Frequency of failure types in percentages, a) Adhesive (failure at adhesive layer, no resin left on dentin), b) cohesive (failure in dentin or luting cement), or c) mixed (combination of adhesive failure between resin and dentin and cohesive failure in the cement) 
Figures:

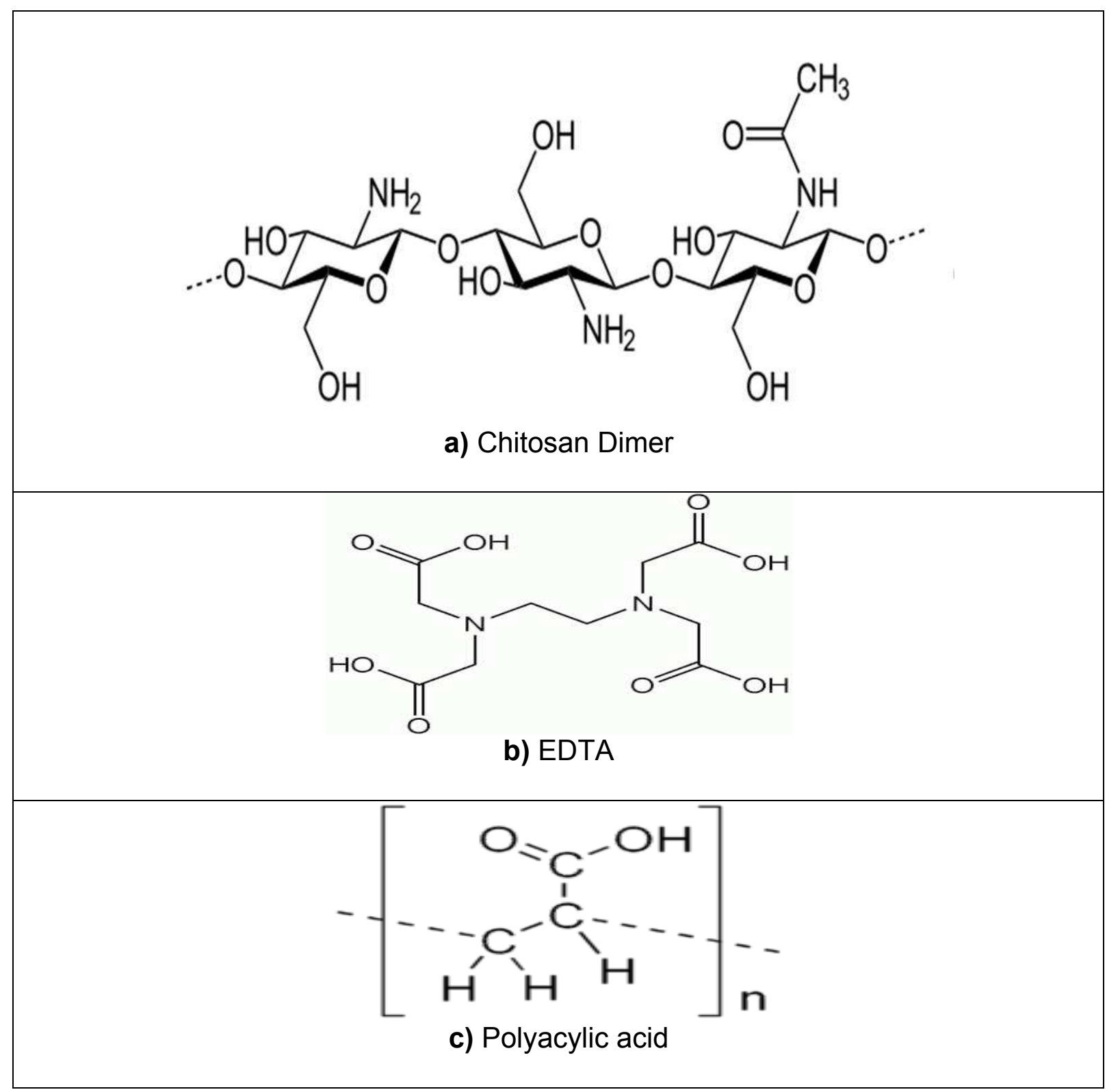

Figs. 1 a-c. Chemical compositions of a) Chitosan Dimer, b) EDTA and c) Polyacrylic acid 

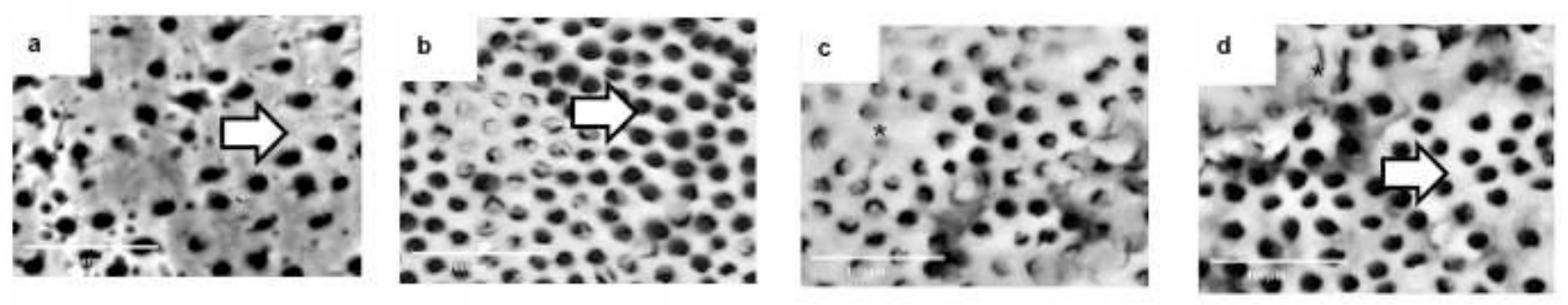

Figs. 2 a-d. Representative SEM images of dentin after debonded dentin beams after a) Adhesive failure in Control group. Note that the dentin tubuli were exposed in large amounts (white arrow), and Mixed failure type in b) Chitosan group, c) EDTA and d) Polyacrylic acid with partial obliteration of dentin tubuli with resin cement $\left(^{*}\right)$ 